\title{
Leg-length in relation to selected ballet performance indicators
}

C. C. Karpodini MSc ${ }^{1}$, M. A. Wyon Phd ${ }^{2}$, N. Comoutos Phd ${ }^{2}$, Y. Koutedakis Phd ${ }^{1,2}$

${ }^{1}$ Research Centre for Sport Exercise and Performance

Institute of Sport

University of Wolverhampton

Walsall, West Midlands, WS1 3BD, UK

${ }^{2}$ School of Exercise Sciences, University of Thessaly, 42100 Trikala, Greece

Author details:

Claire C.C. Karpodini

Claire karpodini@yahoo.gr

C.C.Karpodini@wlv.ac.uk

Tel: $\quad 00302106130474$

Mobile: 00306945466378 


\begin{abstract}
Introduction: It is unclear whether the modern ballet body stereotype of long limbs is advantageous in dance performance. Therefore, we investigated the relationship between leg-length and selected dance movements representative of power, dexterity and range of motion, in ballet dancers at different competence levels.

Methods: The total of 10 recreational, 24 vocational and 10 professional ballerinas volunteered. They were subjected to: a) lower limb length measurements, b) power tests; vertical jump -sautés and unilateral countermovement jump-temps levé, c) dexterity tests; tendus and double battement frappés, and d) flexibility tests; lateral active and passive-développé à la seconde.

Results: For power, regression analyses revealed negative leg-length relationships in recreational (sautés- $p<0.05$; Temps levé $-\mathrm{p}<0.05$ ) and positive leg-length relationships in vocational (sautés $-\mathrm{p}<0.05$ )dancers. We also found negative relationships between leg-length and dexterity in the vocational group (tendus- $\mathrm{p}<0.05$; double battement frappes $-\mathrm{p}<0.05$ ). No significant predictions of leg-length on power, dexterity and range of motion were found in professional dancers. Multiple comparisons revealed significant differences between groups only for dexterity $(p<0.05)$ and range of motion $(p<0.05)$.

Conclusion: Based on selected movements representative of power, dexterity and range of motion, the present data indicate that lower limb length is not a determinative criterion for ballet success. Further studies should investigate whether body stereotypes, such as long limbs, are linked to dance injuries.
\end{abstract}

Key words: Anthropometry, ballet, power, dexterity, range of motion 


\section{Introduction}

Ballet is an activity with specific rules regarding the position of arms, feet and body. It is also an activity linked to high injury rates [1-3] and other medical conditions [4] which can be partly explained by the relatively poor fitness levels [5-8] and/or overwork [9, 10]. Despite of that, many sections of the dance world share the unfounded view that supplementary fitness training away from the dance studios would harm certain aesthetic elements [11, 12]. Yet, the results of a dance-only approach to dance training can be surprising. For instance, although female dancers are stronger than active nondancers, the former demonstrate lower jumps than the latter [13].

Ballet is primarily determined by musical rhythm and movement quality rather than by rules of nature such as force, inertia and gravity [13]. Ballerinas embody ethereal, floating and fast movements, which constitute the basis of their art. However, although ballet body stereotype necessitates long limbs, medium torso and long neck [14-16] anecdotal evidence supports the notion that virtuosic ballet roles have been performed by dancers with relatively longer torso and shorter legs allowing them to move their limbs faster. Nevertheless, a study on 106 dancers has shown the beneficial role of leg length in jumping performance [16]. Interestingly, the same study also revealed a negative association between lower extremity limb length and flexibility. Conflicting data also exist in other sports. In rhythmic gymnastics, for instance, studies have demonstrated both significant [17] and non-significant [18] relationships between anthropometric factors and performance, while others have shown that long legs do not provide substantial biomechanical advantage [19]. Given the contradicting information available thus far, the aim of the present study was to investigate the relationships between leg-length and selected ballet performance indicators representative of power, dexterity and range of motion, in a sample of female ballet dancers at different competence levels.

\section{Methodology}

\section{Participants}

The total of 44 female dancers volunteered. They formed three different groups based on their experience. The first group comprised recreational ballet dancers, members of a youth ballet company $(n=10)$, with an average of 2-3 ballet classes and 2-3 hours of rehearsals per week. The next included vocational ballet students $(n=24)$ engaged in90 
min ballet classes and 90 min contemporary dance daily. The third group involved professional dancers from an elite classical ballet company $(n=10)$; they participated in 90 min ballet classes and 1-3 hours of rehearsals daily. The inclusion criteria included:

a) free of injury for at least three months [16], and b) no extra fitness training or sport activity for at least three months [16]. The study was approved by the Institutional Ethics committee (ref:113270) All volunteers provided a signed informed consent.

\section{Data Collection}

We investigated the relationships between leg length and selected dance movements representative of power, dexterity and range of motion, in ballet dancers at different ability levels. All tests were adjusted to simulate ballet movements. Power was assessed via vertical jump (VJ) in the form of a) sauté in 1st position and b) temps levé in one foot (UCJ -hop step). Dexterity was tested through a) tendus and b) double battement frappés, whereas range of motion was verified laterally (both passively and actively), in the form of developpé à la seconde. All procedures were described and explained to participants and there was a familiarization period. Tests were conducted at the end of the barre during the ballet class with rest intervals of 2-3 minutes. Since static stretching was integrated in the flexibility protocol, power and dexterity tests preceded the flexibility test as previously suggested [16, 20-22]. Measurements were taken from the participants' preference leg [23], which was determined as previously described [24].

\section{Anthropometric Measurements}

Standing height was obtained by a Seca Stadiometer 208 with shoes off, and leg length with the use of an anthropometric tape measuring the distance between the greater trochanter and the lateral malleolus [16]. Weight was obtained by means of a scale.

\section{Power Tests}

\section{a) Vertical Jump (VJ)- Sauté in 1st Position}

The Vertical jump test was employed using a portable power matt (Bosco Ergojump). Participants were asked to perform a countermovement jump taken from 1st position classical ballet with no free hands (sauté in first position, arms bras bas) and plié before every jump. The torso was placed in an upright position throughout the test. The participant completed 3 bilateral countermovement jumps with a 30- second rest period in between attempts; the highest score was recorded. 


\section{b) Unilateral Countermovement Jump - (UCJ). Temps Levé}

The Bosco Ergojump was also used for measuring UCJ height. Participants were asked to perform Temps levé with their preference leg starting with plié, while the other leg was placed in coupé derrière position. Hands were in bras bas position with torso in an upright position. Each participant completed 3 temps levé with a 30-second rest between attempts. The highest score was recorded for further analyses.

\section{Dexterity Tests}

\section{a) Battemement Tendus in 15-second}

Dancers were asked to perform battement tendus à la seconde taken from 1st position with their preference leg within a 15-second period time. Two experienced observers recorded the number of tendus performed during the set period $(15 \mathrm{sec})$. Ballet methodology describes battement tendu à la seconde as a sliding movement starting from close position (in this case from 1st position-turn out) and finishes when the working leg and its toes are fully extended to the side, with toes touching the floor. Then, the working leg slides back closing into 1st position.

\section{b) Double battement Frappés in 15-second}

Participants were asked to perform Double Battement Frappés starting from an open position -à la seconde (leg is extended to the side with toes just above the floor). They were allowed to use their preference leg while two experienced observers recorded the number of double battement Frappés completed within 15 seconds. Although the working leg is placed at an open position, movement occurs mainly at the knee area. The foot of the extended leg is drawn back striking behind and in front of the ankle of the supporting leg, and is then extended out again in the straight position. The foot remains at the coup-de-pied position during the exercise.

\section{Flexibility Tests}

\section{a) Active and passive range of motion}

Range of motion was tested both actively (aROM) and passively (pROM), in the form of Développé à la seconde. For an aROM movement begins with the flexion at the knee and the hip area, external rotation and abduction of the working leg, whereas the foot is fully stretched into coup de pied position. Leg draws upward, towards the knee of the working leg and then is extended to the side. For pROM, participants were asked to 
perform a static stretch by grasping the ankle of their working leg and stretching it to the side, up to their physical ability [16]. Positions were held for 3 seconds. Each participant performed three attempts for aROM and pROM, respectively, which were photographically captured. The greatest aROM and pROM was recorded; the mean difference of each group for active.

\section{Statistical Analyses}

Simple regression analyses were performed to determine whether lower limb length could predict power, dexterity and range of motion in the three studied groups. Multiple comparisons were used to identify changes any trends between group variables. Alpha level of significance was set at $p<0.05$.

\section{Results}

Anthropometric data together with descriptive data from the power, dexterity and ROM test appear in Tables 1 and 2, respectively. Simple regression analysis in recreational dancers revealed negative relationships for lower limb length only on power, $R^{2}=.52$, $F(1,8)=8.76, p<.05$, beta $=-.72,(t=-2.96, p<.05)$ - VJ-sautés; $R 2=.51, F(1,8)=8.19$, $p<.05$, beta $=-.71,(t=-2.86, p<.05)$-UCJ-Temps levé. For vocational dancers we observed positive relationship only on power and more specifically in $\mathbf{V J}$-sautés $R^{2}=$ $.21, F(1,22)=5.86, p<.05$, beta $=.46,(t=2.42, p<.05)$ and negative relationships for lower limb length on dexterity $R^{2}=.19, F(1,22)=5.02, p<.05$, beta $=-.43,(t=-2.24$, $p<.05)$ - tendus; $R^{2}=.21, F(1,22)=6.00, p<.05$, beta $=-.46,(t=-2.45, p<.05)$ double battement frappés. Finally, there were no significant predictions of lower limb length on power, dexterity and range of motion for professional dancers.

Table 1: Anthropometric data

\begin{tabular}{|l|l|l|l|l|}
\hline Groups & $\begin{array}{l}\text { Age } \\
\text { (yrs) }\end{array}$ & $\begin{array}{l}\text { Height } \\
(\mathbf{c m})\end{array}$ & $\begin{array}{l}\text { Mass } \\
(\mathbf{k g})\end{array}$ & $\begin{array}{l}\text { Leg length } \\
(\mathbf{c m})\end{array}$ \\
\hline Recreational & $16 \pm 1.8$ & $1.64 \pm 5.1$ & $49.5 \pm 4.6$ & $79.2 \pm 4.2$ \\
\hline Vocational & $20 \pm 1.9$ & $164.5 \pm 6.9$ & $54.2 \pm 5.4$ & $80.9 \pm 4.0$ \\
\hline Professionals & $36 \pm 9.5$ & $167.4 \pm 5.7$ & $51.2 \pm 5.5$ & $80.5 \pm 4.7$ \\
\hline
\end{tabular}


Table 2: Descriptive data from the power, dexterity and ROM tests

\begin{tabular}{|l|l|l|l|l|l|l|}
\hline Groups & $\begin{array}{l}\text { Tendus } \\
(\mathbf{1 5 s})\end{array}$ & $\begin{array}{l}\text { Double } \\
\text { Battement } \\
\text { Frappés } \\
(\mathbf{1 5 s})\end{array}$ & $\begin{array}{l}\text { Sautés } \\
\mathbf{( \mathbf { c m } )}\end{array}$ & $\begin{array}{l}\text { Temps } \\
\text { levé(UCMJ) } \\
\mathbf{( c m )}\end{array}$ & $\begin{array}{l}\text { aROM } \\
(\mathbf{c m})\end{array}$ & $\begin{array}{l}\text { pROM } \\
\mathbf{( c m )}\end{array}$ \\
\hline Recreational & $30.7 \pm 1.7$ & $20.5 \pm 2.1$ & $27.7 \pm 3.8$ & $14.4 \pm 3.5$ & $112.5 \pm 11.4$ & $148 \pm 13.8$ \\
\hline Vocational & $35.0 \pm 3.6$ & $21.8 \pm 2.7$ & $25.1 \pm 3.7$ & $14.0 \pm 1.9$ & $118.1 \pm 14.7$ & $153.8 \pm 15.6$ \\
\hline Professional & $36.3 \pm 3.3$ & $24.6 \pm 1.8$ & $28.1 \pm 4.0$ & $16.4 \pm 4.3$ & $144.6 \pm 13.8$ & $167.3 \pm 11.3$ \\
\hline
\end{tabular}

Multiple comparisons revealed significant differences between groups in dexterity and flexibility (ROM). In particular, for tendus there were between: a) recreationals and vocationals $(p<0.003)$, and $b)$ recreationals and professionals $(p<0.001)$. For double battement frappés differences were between: a) professionals and recreationals $(p<0.001)$, and $b)$ professionals and vocationals $(p<0.006)$. Furthermore, for aROM, differences were found between professionals and recreationals $(p<0.001)$, whereas for pROM, differences were found between: a) professionals and recreationals $(p<0.002)$, and $b)$ professionals and vocationals $(p<0.010)$.

\section{Discussion}

The aim of the present study was to investigate the relationships between leg-length and selected dance movements representative of power, dexterity and range of motion, in a sample of female ballet dancers ranging from recreational to professional standards. We found no clear evidence that leg-length plays a determinative role for success in ballet. For power, for example, we found negative leg-length relationships in recreational, positive in vocational, and no relationships in professional dancers.

Long levers are advantageous only when the associated muscles are strong enough to bring about their maximum function. A shorter leg can cope with inertia better than a longer one [16], as the later requires greater muscular strength in order to move. The significance of torso-to-legs ratio should also be stressed, as it determines the speed at which muscles can activate body levers [25], as well as the angle of the legs bent in the knee joints at the hip area [26].The positive power found for the vocational dancers is in line with what one might expect from young people involved engaged in demanding training programs. However, the fact that leg-length revealed no relationships for professional in jump height (power), could likewise be attributed to the fact that dancers 
learn to perform in a controlled manner, following very strict and clear body alignments, which focuses in the aesthetic part of the action rather than its physical component [12].

The negative link between leg-length and dexterity found in the current vocational dancers, was probably due to the fact that they were unable to efficiently control their movements due to a combination of factors, such as low level of expertise, increased inertia and/or lack of optimal fitness $[4,5,8,29,30]$. It should be noted that dexterity and development of motor skills are related to length of ballet training [16, 31], which is more likely to occur in professional dancers and that dexterity is not associated to strength given their documented lack of strength training [6, 11, 27, 28]. It is the repetition of standardized ballet movements that may bring about the internalization of the movement pattern for the purposes of creating a motor schema and a special adaptation [31, 32].

The current data revealed no relationships between leg-length and either aROM or pROM in ballet dancers at all three competence levels. This may partly be explained by the fact that ROM exercises are always part of dance auditions, which make flexibility an integral characteristic in most dancers. Besides, ROM is closely associated with hereditary factors $[7,25]$. The inability of the less experienced dancers to keep the height of the leg is probably due to lack of strength at the hip area [33]. Given that dancers do not treat strength training as one of their performance ingredients may account for the aforementioned findings $[6,11,28,34]$. It should be added here that, contrary to the common belief that increased flexibility levels protect against sport injury, this has not been confirmed in elite dancers [35].

Although no significant leg-length relationships were found in most of the studied performance parameters, a trend has been observed whereby the higher the expertise level (from recreational, vocational to professional dancers), the greater the power, dexterity and range of motion. This finding suggests that performance levels are closely linked to length of ballet training rather than influenced by body characteristics $[18,19]$.

It is reasonable to assume that the present results may have been influenced by methodological limitations such as the relatively small number of participants and the lack of data on sitting height-to-leg length ratios which determine the speed at which muscles can activate body levers [25] . 


\section{Conclusions}

Within the current limitations, the present data indicated that leg length does not seem to play a determinative role for success in the ballet movements studied herein. Further studies should investigate whether specific body stereotypes used for aesthetic purposes, such as long limbs, are linked to frequently reported dance injuries.

\section{References}

1. Allen, N., Nevill, A.,Brooks, J.H.,Koutedakis, Y.,Wyon, M.A., The effect of a comprehensive injury audit program on injury incidence in ballet: a 3-year prospective study. Clin. J. Sport Med, 2013. 23: p. 373-378.

2. Allen, N., et al., Ballet injuries: injury incidence and severity over 1 year. J Orthop Sports Phys Ther, 2012. 42(9): p. 781-90.

3. Koutedakis, Y., kahlouja, M., Pacy, P.J., Murphy, M. Dunbar, G.M.J., Thigh peak torques and lower-body injuries in dancers. J. Dance Med. Sci 1997. 1(1): p. 12-15.

4. Koutedakis, Y., Jamutras, A., The dancer as a performer athlete: physiological considerations. Sports Med, 2004. 34(10): p. 651-661.

5. Brinson, P., Fit to dance?:Report of the National Injury into Dancer's Health and injury. 1st ed. 1996: Calouste Gulbenkian Foundation.

6. $\quad$ koutedakis, Y., Hukam, H., Metsios, G., Nevill, A., Giakas, G., Jamutras, A., Myszekewycz, L., The effects of three months of aerobic and strength training on selected performance and fitness related parameters in modern dance students. J Strength Cond Res, 2007. 21(3): p. 808-812.

7. Koutedakis, Y., Sharp, N.C.C., The fit and healthy dancer. 1999: John Wiley \& Sons Ltd, Chichester England.

8. $\quad$ Laws, H., Fit to dance 2. 1st ed. 2005: Dance UK.

9. $\quad$ koutedakis, Y., Budgett, R., Faulmann, L., Rest in underperforming elite competitors $\mathbf{J}$ Dance Med Sci, 1990. 24(4): p. 248-252.

10. koutedakis, Y., Myszkewycz, L., Soulas, D., Papapostolou, V., Sharp, N.C.C., The effects of rest and subsequent training on selected physiological parameters in professional female classical dancers. Int J Sports Med, 1999. 20(6): p. 379-383.

11. Koutedakis, Y., Stavropoulos -Kalinoglou, A., Metsios, G., The significance of muscular strength in dancers. J Dance Med Sci, 2005. 9(1): p. 29-34.

12. Harley, Y.X.R., Gibson, A.S.C., Harley, E.H., Lambert, M.I., Vaughan, C.L., Noakes, P.D. , Quadricepts Strength and Jumping Efficiency in Dancers. J Dance Med Sci, 2002. 6(3).

13. Laws, K., Physics and the art of dance: Understanding movement. 2nd ed. 2008: Oxford Univercity Press.

14. Hamilton, L., Brooks-Gynn, J., Warren, M., Hamilton, M., The impact of thiness and dieting on the professional ballet dancer. Medical Problems of Performing Artists, 1987. 2: p. 117-122.

15. Lumley, M. A high Point of Ballet Training. 2000 [cited 2014 December 15].

16. Wyon, M., Nevill, A.M., Dekker, K., Brown, D.D., Clarke, F., Pelly, J., Koutedakis, Y., Effect of leg length on ROM, VJ, and leg dexterity in dance. Int J Sports Med, 2010. 31(9): p. 631-635.

17. Douda, H.T., Toubekis, A.G., Avloniti, A.A., Tokmakidis, S.P., Physiological and anthropometric determinants of rhythmic gymnastics performance. Int J Sports Physiol Perform, 2008. 3(1): p. 41-45. 
18. Alexander, M.J.L., The physiological characteristics of elite rhythmic sportive gymnasts. J hum M, 1989. 17: p. 49-69.

19. Arazi, H., Farajil, H., Mehrtash, M., Anthropometric and physiological profile of Iranian Junior elite gymnasts. Physical Education and Sport, 2013. 11(1): p. 35-61.

20. Wyon, M., Allen, N., Angioi, M., Nevill, A., Twitchett, E., Anthropometric factors affecting vertical jump height in ballet dancers. J Dance Med Sci, 2006. 10(3): p. 106110.

21. Bradley, P.S., Olsen, P.D., Portas, M.D., The effects of static ballistic and proprioceptive neuromuscular facilitation stretching on vertical jump performance J Strength Cond Res, 2007. 21(1): p. 223-226.

22. Golomer, E., Fery, Y.A., Unilateral jump behavior in young professional female ballet dancers. Int J Sports Med, 2001. 110(1-2): p. 1-7.

23. Kimmerle, M., Lateral bias, functional asymmetry, dance training and dance injuries $\mathbf{J}$ Dance Med Sci, 2010. 14(2): p. 58-66.

24. Schneiders, A.G., Suillivan, S.J., O'Malley, K.J., Clarke, S.V., Knappstein, S.A., Taylor, L.J., A valid and reliable clinical determination of foodness. American Academy of Physical Medicine and Rehabilitation, 2010. 2(9): p. 835-841.

25. Cuk, I., Pajek, M.B., Jakse, B., Pajek, J., Pecek, M., Morphologic Bilateral Differences of Top Level Gymnasts. Int Journal of Morphology, 2012. 30(1): p. 110-114.

26. Gruodytè, R., Jürimäe,T., Bone Mineral Density and Jumping Height in pre-menarcheal and post menarcheal physically active girls. Education. Physical Training. Sport, 2011. 82(3): p. 3-8.

27. Angioi, M., Metsios, G.S., Twitchett, E., Koutedakis, Y., Wyon, M., Association between physical fitness parameters and aesthetic competence in contemporary dancers. J Dance Med Sci, 2009. 13(4): p. 115-123.

28. $\quad$ koutedakis, Y., Sharp, N.C.C., Thigh-muscles strength training dance exercise dynamometry and anthropometry in professional ballerinas. J Strength Cond Res, 2004. 18(4): p. 714-718.

29. Bennell, K., Khan, K.M., Matthews, B., De Gruyter, M., Cook, E., Holzer, K. Wark, D., Hip and ankle range of motion and hip muscle strength in young female ballet dancers and controls. Br J Sports Med, 1999. 33(5): p. 340-346.

30. Brown, G.A., Wells, T. J., Schade, L.M., Smith, D. L.,Fehling, P. C., Effects of Plyometric Training Versus Traditional Weight Training on Strength, Power, and Aesthetic Jumping Ability in Female Collegiate Dancers. J Dance Med Sci, 2007. 11(2): p. 38-44.

31. Lee, H.H., Lin, C.W., Wu,H.W., Wu, T.C., Lin, C.F., Changes in biomechanics and muscle activation in injured ballet dancers during a jump-land task with turnout (Sissonne Fermée). J Sports Sci, 2012. 30(7): p. 687-697.

32. Enoka, R.M., Neural adaptations with chronic physical activity J Biomech, 1997. 30(5): p. 447-455.

33. Grossman, G., Wilmerding, M., The Effect of Conditioning on the Height of Dancer's Extension in à la Seconde. J Dance Med Sci, 2000. 4(4): p. 117-121.

34. Koutedakis, Y., Dick F., Pacy, P.J., Health and fitness in professional dancers. Medical Problems of Performing Artists, 1997. 21(1): p. 23-27.

35. Koutedakis, Y., Frischknecht, R., Murphy, M., Knee flexion to extension peak torque ratios and low-back injuries in highly active individuals. Int J Sports Med, 1997. 18(4): p. 290-295. 